\title{
Mutual Information Based Analysis for the Distribution of Financial Contagion in Stock Markets
}

\author{
Xudong Wang and Xiaofeng Hui \\ School of Management, Harbin Institute of Technology, Harbin 150001, China \\ Correspondence should be addressed to Xiaofeng Hui; xfhui@hit.edu.cn \\ Received 2 June 2017; Accepted 1 October 2017; Published 25 October 2017 \\ Academic Editor: Luisa Di Paola
}

Copyright (c) 2017 Xudong Wang and Xiaofeng Hui. This is an open access article distributed under the Creative Commons Attribution License, which permits unrestricted use, distribution, and reproduction in any medium, provided the original work is properly cited.

\begin{abstract}
This paper applies mutual information to research the distribution of financial contagion in global stock markets during the US subprime crisis. First, we symbolize the daily logarithmic stock returns based on their quantiles. Then, the mutual information of the stock indices is calculated and the block bootstrap approach is adopted to test the financial contagion. We analyze not only the contagion distribution during the entire crisis period but also its evolution over different stages by using the sliding window method. The empirical results prove the widespread existence of financial contagion and show that markets impacted by contagion tend to cluster geographically. The distribution of the contagion strength is positively skewed and leptokurtic. The average contagion strength is low at the beginning and then witnesses an uptrend. It has larger values in the middle stage and declines in the late phase of the crisis. Meanwhile, the cross-regional contagion between Europe and America is stronger than that between either America and Asia or Europe and Asia. Europe is found to be the region most deeply impacted by the contagion, whereas Asia is the least affected.
\end{abstract}

\section{Introduction}

From the "Black Monday" in 1987 to the recent European sovereign debt crisis, the world has experienced several severe financial crises in the past few decades [1]. These crises spread panic in markets, causing not only a plunge in assets prices but also a grave deterioration of the financial and economic systems. Usually, the shock caused by the financial crisis is not confined to the country of its origin. It also affects other countries, spreading like a contagious virus [2]. To study this phenomenon, researchers introduced the concept of financial contagion. In this paper, we adopt the widely used definition from Gallegati et al. [3-5]. They defined financial contagion as a significant increase in cross-market linkages after a shock to one country or group of countries [6].

As globalization is one of the main features of the contemporary world economy, researching financial contagion is helpful for investors and policymakers [7-9]. This field has already attracted many studies. For example, Caporale and Arestis examined the Asian stock markets during the 1997 Asian financial crisis and found evidence of contagion $[10,11]$.
Using a regression-based approach, Van Horen et al. tested the data of five Asian foreign exchange markets [12]. To analyze the US subprime crisis, Chen et al. applied a multifractal volatility method to study the high frequency data of the US and Chinese stock markets [13]. Dungey et al. studied the daily data of stock indices using different methods. All of them discovered evidence for contagion [14-16]. Wen and Guo explored the contagion effect across different types of markets $[17,18]$. To understand the European sovereign debt crisis, Suh analyzed sovereign debt yields data and discovered that the contagion varies drastically with time [19]. Ahmad and Dewandaru explored the contagion in stock markets and discovered evidence of its impact [20,21]. Shen et al. researched the contagion effect of the European debt crisis on the Chinese market. They found that the contagion had a significant influence on the macro economy channel but limited impact on the psychology of investors in the Chinese market [22].

In this paper, we apply mutual information (MI) to research financial contagion. The correlation coefficient, Kendall's tau, Spearman's rho, and copula are typical 
statistical methods for measuring financial contagion [6, 2325]. However, the correlation coefficient can only measure linear correlation and cannot capture nonlinear dependence commonly observed in stock markets [26, 27]. Kendall's tau and Spearman's rho can only detect the monotonic functional dependence [28]. Although copula can capture both linear and nonlinear dependence, one needs to select certain copula functions before adopting it as a method [29]. This introduces an element of subjectivity. Compared with these methods, MI has three main advantages. First, it measures both linear and nonlinear dependence [30-32]. Second, it does not make any assumption on the underlying relationship of the variables [33]. Thus, it is independent of the model and completely data driven. Third, it is robust to noise [34]. There are also two main drawbacks of MI. It is computationally expensive and its analytical statistical test is generally unavailable $[35,36]$. The bootstrap method can be used to infer the statistical features of MI [37]. As computer technology advances, the computation time taken by a personal computer is acceptable and MI has already been applied in many disciplines [38-43].

This article researches financial contagion using a multimarket perspective and concentrates on the regional characteristics of the markets affected by the contagion. It mainly studies the following questions:

(1) How is the financial contagion distributed in the stock markets?

(2) How does the distribution of the contagion evolve during the crisis period?

(3) Which region is impacted most by the financial contagion? Which one is the least affected?

The rest of this paper is organized as follows. Section 2 introduces the data and methods. Section 3 displays the empirical results and gives some analyses and discussions. Section 4 concludes the paper.

\section{Data and Methods}

2.1. Data. In this paper, 32 stock markets were researched for analyzing the US subprime crisis, which delivered a strong shock to the world's economy. These markets span four continents and we divide them into three groups, according to their geographical location. All data was downloaded from the WIND database which is a commercial finance information provider in China. We choose the same time range and period division in the literatures $[44,45]$. The data is from January 3, 2005, to December 7, 2009. This range is further divided into the precrisis and crisis period. The precrisis period extends from January 3, 2005, to July 31, 2007. The crisis period begins on August 1, 2007, and ends on December 7, 2009 [44, 45]. Table 1 displays the names and numbers of these countries (or regions) and their stock indices.

As stock markets are not open on weekends and festivals, the data is unavailable on these days. To deal with this circumstance, we follow Chiang and Voronkova to consider that the stock price stays the same as the latest trading day $[46,47]$.
Since different markets have different trading hours, Forbes and Rigobon applied rolling average two-day return to deal with the effect [6]. However, it was found that the results obtained were not significantly different. A drawback with this method is that it tends to introduce serial correlation [46]. Considering the weekly return was another solution proposed by researchers [48], but most of the daily information gets ignored in this approach. The lagged return method was also considered in the literature [49]. However, this approach may bring in more random noise [50]. Therefore, we leave this topic for future research and follow the literatures $[16,25,45,51]$ by using unlagged daily data in this paper.

The logarithmic returns for daily closing price are calculated by formula (1) and we use them for further computation. All computation programs are implemented by MATLAB software.

$$
R(t)=\ln P(t)-\ln P(t-1),
$$

where $R(t)$ stands for the logarithmic return and $P(t)$ and $P(t-1)$ denote the daily closing price of time $t$ and time $t-1$, respectively.

\subsection{Methods}

2.2.1. MI. To introduce MI, we at first present the Shannon entropy $H(X)$ which is crucial for information theory. It is defined as

$$
H(X)=-\sum_{x \in X} p(x) \log p(x),
$$

where $p(x)$ is the probability of $x$. It measures the extent of uncertainty. The base of the logarithm is commonly chosen as 2; the unit is the bit.

Another important concept is the joint entropy $H(X, Y)$ which is described as

$$
H(X, Y)=-\sum_{x \in X} \sum_{y \in Y} p(x, y) \log p(x, y),
$$

where $p(x, y)$ is the joint probability of $x$ and $y$.

The definition of MI between $X$ and $Y$ is given in the following formula [52]:

$$
\operatorname{MI}(X, Y)=\sum_{x \in X} \sum_{y \in Y} p(x, y) \log \frac{p(x, y)}{p(x) p(y)} .
$$

According to formulas (2) and (3), MI could be rewritten as the following formula [53]:

$$
\operatorname{MI}(X, Y)=H(X)+H(Y)-H(X, Y) \text {. }
$$

MI measures the information which one variable discloses about another one. And if two variables are interdependent, their MI will be greater than zero. Stronger interdependence produces larger MI [31].

We concentrate on the extreme events that are usually caused by financial crises. With reference to Dimpfl et al. [5457], the 0.05 and 0.95 quantiles are suitable thresholds for 
TABLE 1: Details of the 32 countries (or regions) and their stock indices.

\begin{tabular}{|c|c|c|c|}
\hline & Number & Country (region) & Index \\
\hline \multirow{13}{*}{ Asia and Oceania } & 1 & Australia & AORD \\
\hline & 2 & China & SSE \\
\hline & 3 & Hong Kong & HSI \\
\hline & 4 & India & SENSEX \\
\hline & 5 & Indonesia & JKSE \\
\hline & 6 & Japan & N225 \\
\hline & 7 & Korea & KS11 \\
\hline & 8 & Malaysia & KLSE \\
\hline & 9 & New Zealand & NZ50 \\
\hline & 10 & Philippines & PSI \\
\hline & 11 & Singapore & STI \\
\hline & 12 & Taiwan & TWII \\
\hline & 13 & Thailand & SETI \\
\hline \multirow{13}{*}{ Europe } & 14 & Czech Republic & PX \\
\hline & 15 & Finland & HEX \\
\hline & 16 & France & FCHI \\
\hline & 17 & Germany & GDAXI \\
\hline & 18 & Italy & ITLMS \\
\hline & 19 & Netherlands & AEX \\
\hline & 20 & Norway & OSEAX \\
\hline & 21 & Poland & WIG \\
\hline & 22 & Portugal & BVLX \\
\hline & 23 & Russia & RTS \\
\hline & 24 & Spain & IBEX \\
\hline & 25 & Sweden & OMXSPI \\
\hline & 26 & United Kingdom & FTSE \\
\hline \multirow{6}{*}{ America } & 27 & Argentina & MERV \\
\hline & 28 & Brazil & IBOVESPA \\
\hline & 29 & Canada & GSPTSE \\
\hline & 30 & Chile & IPSA \\
\hline & 31 & Mexico & MXX \\
\hline & 32 & United States & DJI \\
\hline
\end{tabular}

the normal and extreme values, respectively. We follow the method of Dimpfl and Sensoy $[54,55]$ to symbolize the stock returns using formula (6). Symbol 0 means normal returns, whereas the symbols -1 and 1 stand for extreme returns. The range of symbol 0 keeps wide to reduce the effect of normal pattern [55].

$$
S(t)= \begin{cases}-1 & R(t) \leq q_{\alpha} \\ 0 & q_{\alpha}<R(t)<q_{1-\alpha} \\ 1 & q_{1-\alpha} \leq R(t),\end{cases}
$$

where $\alpha=0.05$ and $q_{\alpha}$ and $q_{1-\alpha}$ are the $\alpha$ and $1-\alpha$ quantiles, respectively. After the symbolization, we calculate the MI according to the above definitions. In order to examine the robustness of the results, we also analyzed the results obtained by using $\alpha=0.01, \alpha=0.1$, and $\alpha=0.15$.
2.2.2. Contagion Test and Measure. In this article, we concentrate on the regional features of the financial contagion, and thus we follow the literatures $[8,58,59]$ to adopt an undirected symmetric measure.

Following the definition of Gallegati [3], contagion occurs when the cross-linkages between markets increase significantly after a financial shock. We test this by examining whether the MI rises significantly after the US subprime crisis breaks out.

For the period $t$ which is the entire or a sliding window of the crisis period, let $X$ and $Y$ be two symbolized stock return series; the null hypothesis supposes that there is no significant increase of MI and no contagion between $X$ and $Y$. The hypotheses are described as follows:

$$
\begin{aligned}
& H_{0}: \mathrm{MI}_{\text {pre }}^{X Y}-\mathrm{MI}_{t}^{X Y} \geq 0 \\
& H_{1}: \mathrm{MI}_{\text {pre }}^{X Y}-\mathrm{MI}_{t}^{X Y}<0,
\end{aligned}
$$


where $\mathrm{MI}_{\text {pre }}^{X Y}$ and $\mathrm{MI}_{t}^{X Y}$ are the MI values of $X$ and $Y$ during the precrisis period and period $t$, respectively.

Here, we apply the block bootstrap method for the statistical inference. For time series $z_{1}, z_{2}, \ldots, z_{n}$, its procedure is as follows [60].

Let $L$ be the block length which is far less than $n$. With reference to Cheng et al. [61], we take $L$ as $n^{1 / 3}$ in this paper. We can get $n-L+1$ overlapping blocks as the following formula:

$$
\begin{aligned}
& \left(z_{1}, z_{2}, \ldots, z_{L}\right), \ldots,\left(z_{i}, z_{i+1}, \ldots, z_{i+L-1}\right), \ldots, \\
& \quad\left(z_{n-L+1}, z_{n-L+2}, \ldots, z_{n}\right) .
\end{aligned}
$$

Step 1. Sample uniformly with replacement to choose $k+1$ blocks out of the $n-L+1$ blocks where $k=$ floor $(n / L)$; floor $(\cdot)$ is the function which gets the integral part.

Step 2. Lay the $k+1$ blocks end to end and abandon the last $L-m$ data where $m=n-k L$. Then, we get a bootstrap sample $z_{1}^{b}, z_{2}^{b}, \ldots, z_{n}^{b}$.

We implement the above procedures 1000 times on the precrisis period and period $t$ data of $X$ and $Y$. We sample $X$ and $Y$ simultaneously. This means whenever $x_{r}$ is selected, $y_{r}$ is selected [62]. We calculate every time the MI values $\mathrm{MI}_{\text {pre }}^{b}$ and $\mathrm{MI}_{t}^{b}$ for the two bootstrap samples of the precrisis period and period $t$. Then, their difference $d_{t}^{b}=\mathrm{MI}_{\text {pre }}^{b}-\mathrm{MI}_{t}^{b}$ is computed.

At last, we could get the distribution of $d_{t}^{b}$ which is approximate to that of $\mathrm{MI}_{\text {pre }}^{X Y}-\mathrm{MI}_{t}^{X Y}$. With reference to Mills and Shrout $[63,64]$, we can get the one-side bootstrap confidence interval $\left(-\infty, c_{1-\beta}\right]$, where $c_{1-\beta}$ is the $1-\beta$ quantile of the $d_{t}^{b}$ distribution. In this paper, we take $\beta$ as $5 \%$. If 0 is not in the confidence interval, the null hypothesis is rejected at the significance level of $\beta$. Thus, we can consider that the contagion happens in period $t$. Otherwise, we consider there is no contagion.

Following Da Silva et al. [59], we adopt the increment in interdependence to measure the contagion strength (CS). If there exists contagion between the indices $X$ and $Y$ in period $t$, we represent $\mathrm{CS}_{t}^{X Y}$ as shown in formula (9). If there is no contagion, $\mathrm{CS}_{t}^{X Y}$ is 0 .

$$
\mathrm{CS}_{t}^{X Y}=\mathrm{MI}_{t}^{X Y}-\mathrm{MI}_{\text {pre }}^{\mathrm{XY}} .
$$

The total contagion strength (TCS) of the market $i$ affected is defined as the sum of contagion strength with other stock markets, as shown in the formula below:

$$
\operatorname{TCS}_{t}^{i}=\sum_{j=1}^{m} \operatorname{CS}_{t}^{i j}
$$

where $m$ is the number of other stock markets.

To measure the contagion intensity of a group of markets, we define a variable called the group average contagion strength (GACS). The GACS for group $h$ is the average TCS of all markets in the group. It is given by the following formula:

$$
\operatorname{GACS}_{t}^{h}=\frac{1}{u} \sum_{j=1}^{u} \mathrm{TCS}_{t}^{j},
$$

where $u$ is the number of the markets in the group $h$.

To measure the cross-contagion strength of two groups, we use average cross-group contagion strength (ACGCS). For the groups $p$ and $q$, the ACGCS $_{p q}$ is the average contagion shared by a country in group $p$ with a country in group $q$. It is symmetric for groups $p$ and $q$ and is defined as

$$
\operatorname{ACGCS}_{t}^{p q}=\frac{1}{a b} \sum_{k=1}^{a} \sum_{j=1}^{b} \operatorname{CS}_{t}^{k j},
$$

where $a$ and $b$ are the numbers of countries in groups $p$ and $q$, respectively.

2.2.3. Maximum Spanning Tree. Maximum spanning tree (MaxST) is a useful tool to analyze the structure of graphs $[65,66]$. We use it in this study to analyze the structure of the contagion distribution. Kruskal's algorithm is generally used to construct a minimum spanning tree. Following Sarkar et al. [67], we modify it to build MaxSTs by taking the edges of the graph which maximize the sum of weights instead of minimizing it. The edge weight corresponds to the contagion strength. At the same time, the color map method, which is a convenient way to visualize the contagion spread, is applied.

In order to investigate the evolution of the contagion distribution, we apply the sliding window method during the crisis period. Jaccard similarity coefficient (JSC) [68] is adopted to measure the similarity of the MaxSTs of two consecutive windows. Formula (13) describes its definition.

$$
\operatorname{JSC}(A, B)=\frac{|G(A) \cap G(B)|}{|G(A) \cup G(B)|},
$$

where $|G(A) \cap G(B)|$ means the number of the same edges in graphs $A$ and $B .|G(A) \cup G(B)|$ is the number of the edges in the union set of graphs $A$ and $B$.

\section{Empirical Results and Discussions}

As it is lengthy to show the MI evolution of all stock markets, we at first analyze the evolution of the MI values between the US and G7 countries. These countries are chosen as they play a significant role in the world's finance and economy. The sliding windows are with the length of 300 days and the slide step is 10 days. From the results shown in Figure 1, we find that the curves could be divided into two parts at the 100th window, which begins on September 21, 2007. This is near the start of the subprime crisis. Before that time, the MI values between these countries are relatively low. However, after that time, a sudden spike is witnessed in all curves. This indicates an increase in interdependence and financial contagion.

Table 2 describes the statistical properties of the MI values between the 32 stock indices. We can see that the value of average MI during the crisis period is larger than that 
TABLE 2: Descriptive statistics of the MI values for the 32 stock indices.

\begin{tabular}{lccccc}
\hline Period & Mean & Std. & Skewness & Kurtosis & Jarque-Bera statistic \\
\hline Precrisis & 0.0237 & 0.0211 & 1.9304 & 7.5004 & $1453.2761^{* * *}$ \\
Crisis & 0.1101 & 0.0850 & 1.8548 & 7.0615 & $1250.6198^{* * *}$ \\
\hline
\end{tabular}

Note. $* * *$ means significance at $0.1 \%$ level.

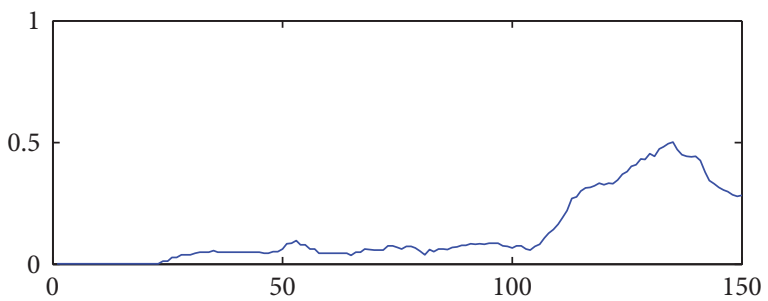

- US-Canada

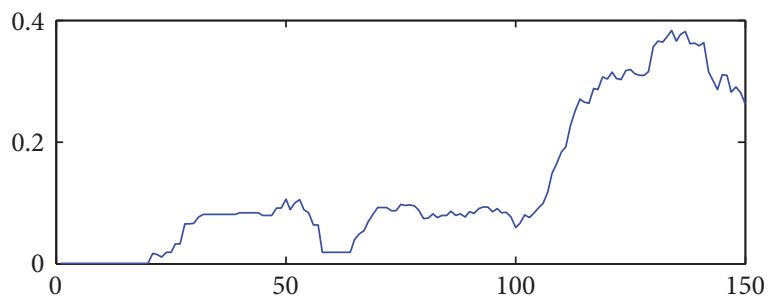

- US-France

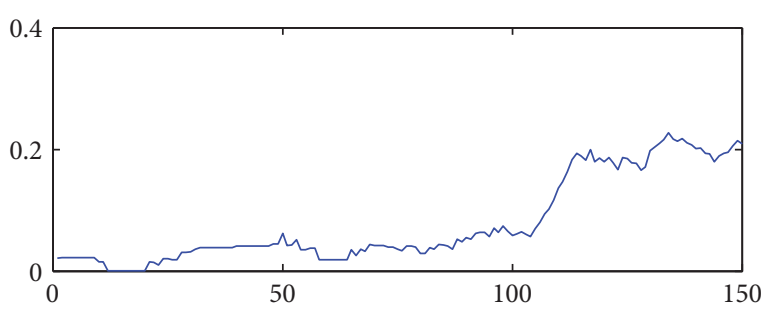

- US-Italy

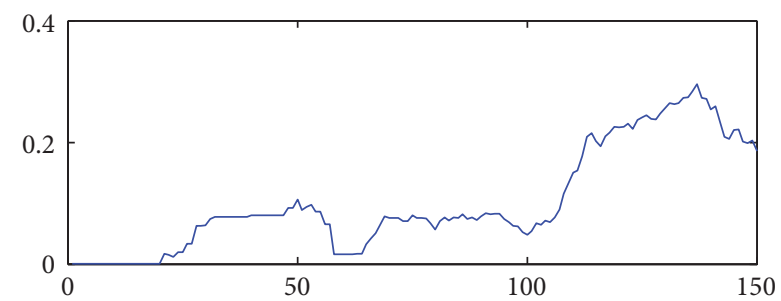

- US-UK

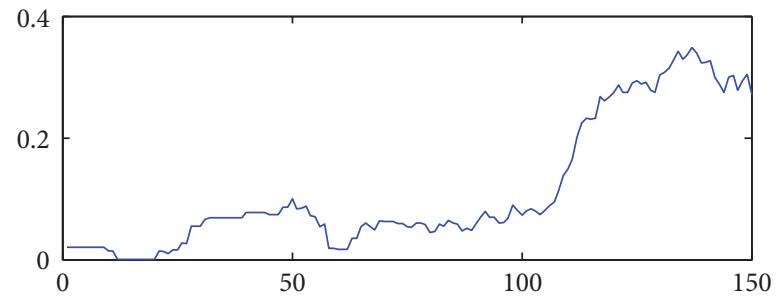

US-Germany

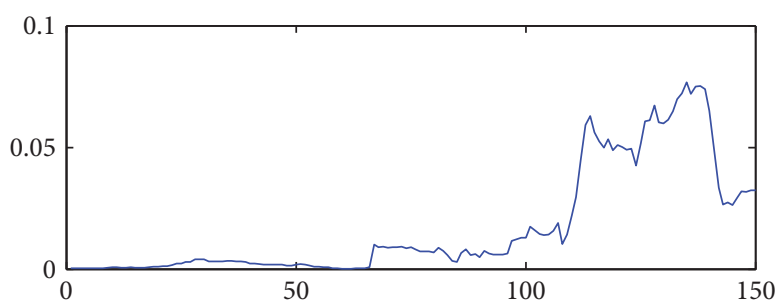

- US-Japan

FIGURE 1: The evolution of the MI values between US and G7 countries.

during the precrisis period. In Figure 2, we observe that the precrisis probability density curve is leptokurtic. The values concentrate around the mean value. During the crisis period, the probability density and cumulative functions support the notion that the values are more varied and usually larger.

We test the financial contagion between every pair of the stock markets and get a contagion matrix $(\mathrm{CM})$ with the size of $32 \times 32$. The value of $\mathrm{CM}(i, j)$ is the contagion strength $\mathrm{CS}_{t}^{i j}$ defined in formula (9). Figure 3 shows the color map of the $\mathrm{CM}$ for the entire crisis period. The numbers on the row and column axes are the numbers of the stock markets in Table 1. The color reflects the contagion strength.

In Figure 3, we find the widespread existence of the financial contagion phenomenon; moreover, it is found that its strength varies across markets. There are two regions in the map showing strong contagion. The first one is in the upper right corner corresponding to markets number 14 to number 32. These are the European and American markets, which show a strong effect of contagion. The other one is in the lower left corner corresponding to markets number 1 to number 13; however, the intensity of contagion in these markets is relatively lower. These are the Asian and Oceanian countries. The level of contagion in the remaining parts of the map is quite low. This indicates that markets in Asia and Oceania mainly share contagion with their geographical neighbors and have mild contagion with European and American countries. Despite relatively strong cross-regional contagion in the European and American region, we can still divide it into two subparts. The first subpart covers countries number 14 to number 26, all of which are in Europe. The second one is due to countries number 27 to number 32, which are all in the American region. Thus, it can be inferred that countries tend 
TABLE 3: Descriptive statistics of the contagion strength for the entire crisis period.

\begin{tabular}{cccccc}
\hline & Mean & Std. & Skewness & Kurtosis & Jarque-Bera statistic \\
\hline Contagion strength & 0.0848 & 0.0708 & 1.6164 & 6.1661 & $846.3200^{* * *}$ \\
\hline
\end{tabular}

Note. $* * *$ means significance at $0.1 \%$ level.

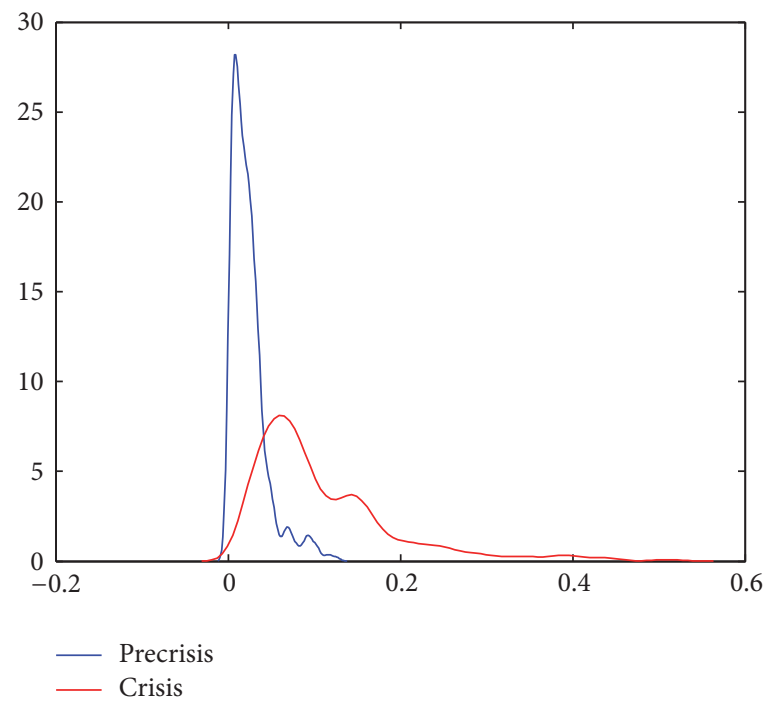

(a)

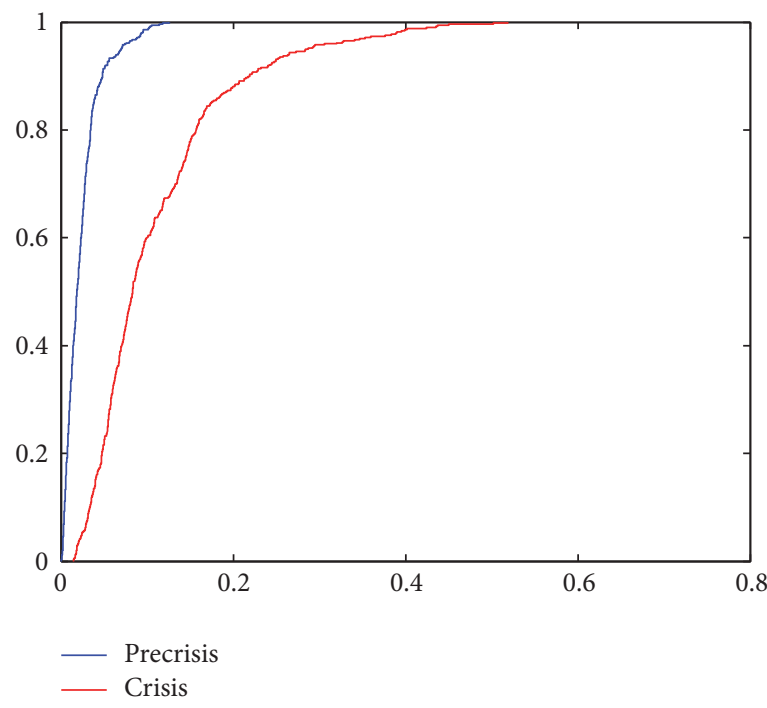

(b)

Figure 2: The probability density function curves (a) and the cumulative probability function curves (b) for the MI values of the entire precrisis and crisis periods.

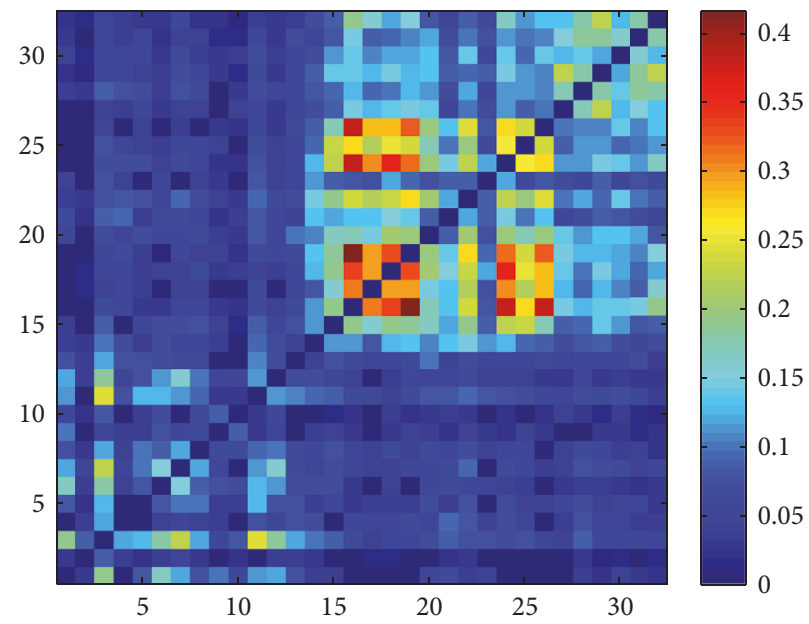

FIgURE 3: The color map of the contagion distribution for the entire crisis period.

to share contagion more with their geographical neighbors. The GACS values for the Asian, European, and American regions are $1.7262,3.4823$, and 2.7393 , respectively.

We construct the MaxST according to the CM. Figure 4 describes the MaxST for contagion distribution during the entire crisis period. We can see that the nodes with the same symbol are connected with each other, which means that those in the same region tend to cluster.
Table 3 shows the statistics of the contagion strength across markets for the entire crisis period. It is inferred that the distribution does not follow a Gaussian distribution. It is right skewed, with a steeper peak.

In order to explore the evolution of the contagion distribution, we study it in each sliding window. The beginning time is the time which the subprime crisis began at. The window length is 300 days. And the slide step is 14 days. There 


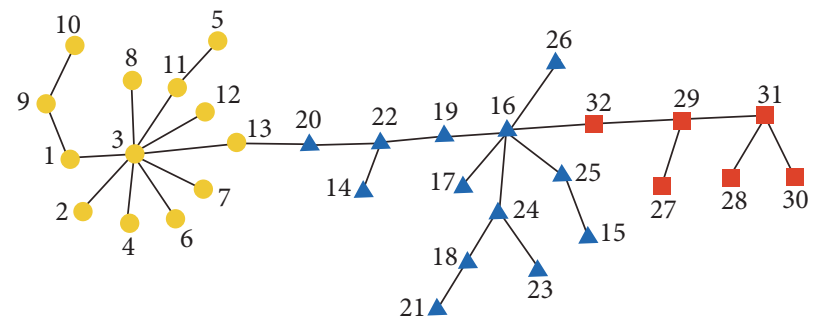

FIgURE 4: The MaxST of the contagion distribution for the entire crisis period. Asian and Oceanian markets are shown as yellow circles. European markets are shown as blue triangles. American markets are shown as red squares.

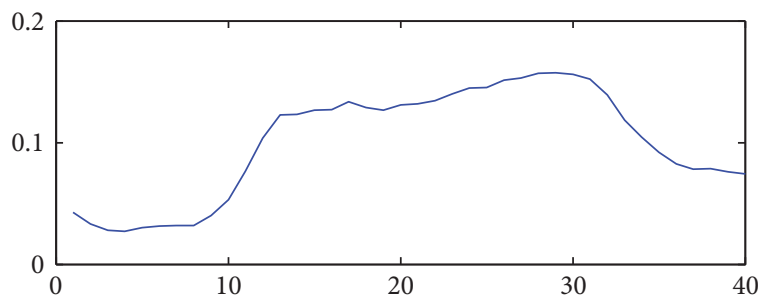

- Mean

(a)

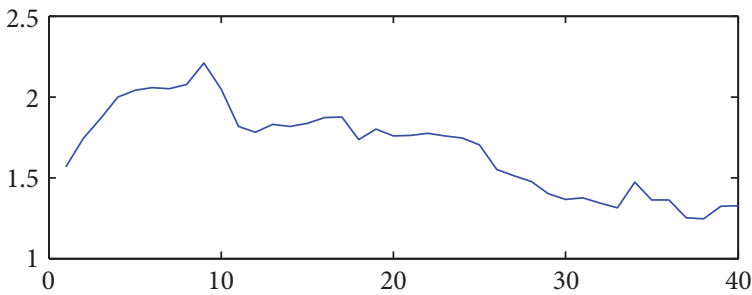

(c)

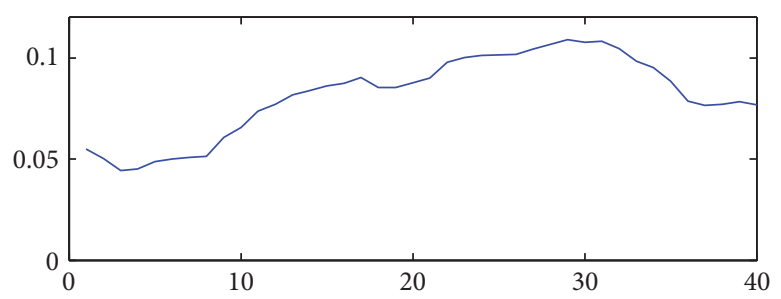

- Std.

(b)

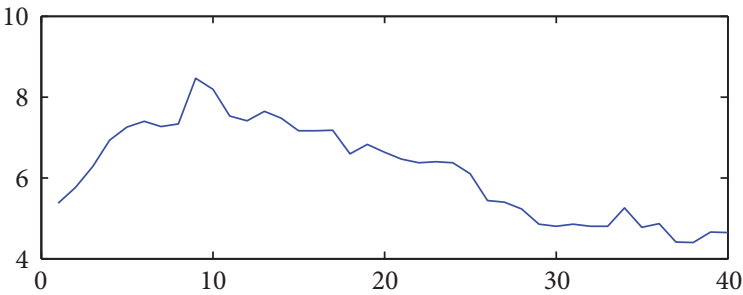

— Kurtosis

FiguRE 5: Statistics of the contagion strength across markets for every window. The average (a), standard deviation (Std.) (b), skewness (c), and kurtosis (d) values.

are 40 windows in total. Figure 5 shows the statistics of the contagion strength in every window.

It can be observed that the mean value is low at the beginning and then witnesses an uptrend. Around the 30th window, the value starts to decrease but is still higher than that at the beginning of the selected time span. The standard deviation also increases gradually at first and gets smaller in the closing phase. The skewness is always above 0 and the kurtosis is above 3, indicating that the distribution is positively skewed and leptokurtic. The Jarque-Bera tests are all significant at the $0.1 \%$ level, confirming that the distribution is not normal.

We select four representative windows to display the color maps. The 5th, 15th, 25th, and 35th windows are selected. And the starting dates of the windows are 2007.9.27, 2008.2.14, 2008.7.3, and 2008.11.20, respectively. The 5th window represents the early stage of the crisis. The 15 th and 25 th windows cover the middle stage. The 35 th window is from the late phase of the crisis. Figure 6 shows the color maps for these windows. In order to compare them, the color bar has been adjusted to the same range.

From Figure 6, it can be found that the contagion strength is very low in the 5th window. The European region and Asian region, which includes two Oceanian countries, have relatively stronger contagion. The contagion in the American region is weak. Moreover, the cross-regional contagion effect of the three regions is slight. In the 15th window, the contagion intensity has increased. All three regions show greater contagion and the cross-regional contagion gets stronger as well. In the 25th window, the contagion strength continues to grow. In the 35th window, the contagion starts to weaken. However, both Europe and America display a relatively strong contagion effect. The contagion in the Asian region has become mild. The cross-regional contagion exists mainly between the European and American markets. From the figure, we can conclude that contagion is relatively weak early 


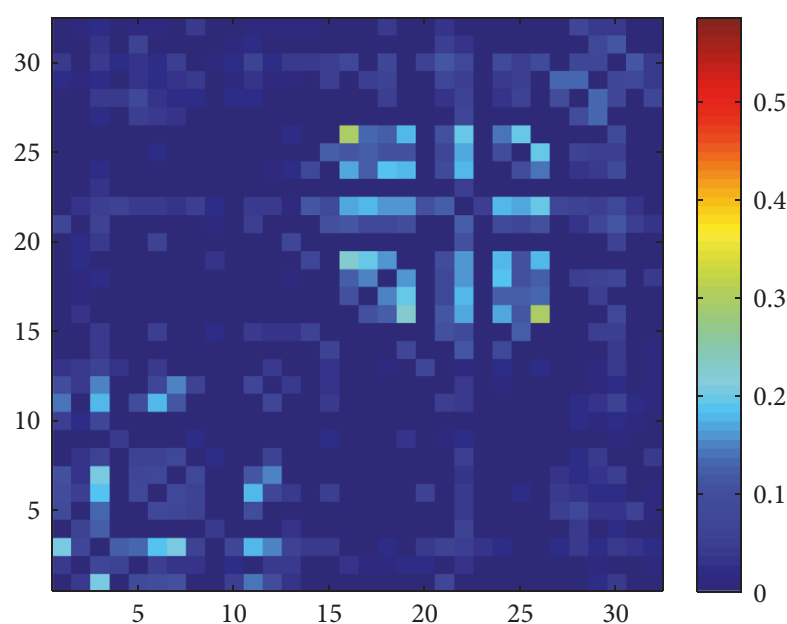

(a)

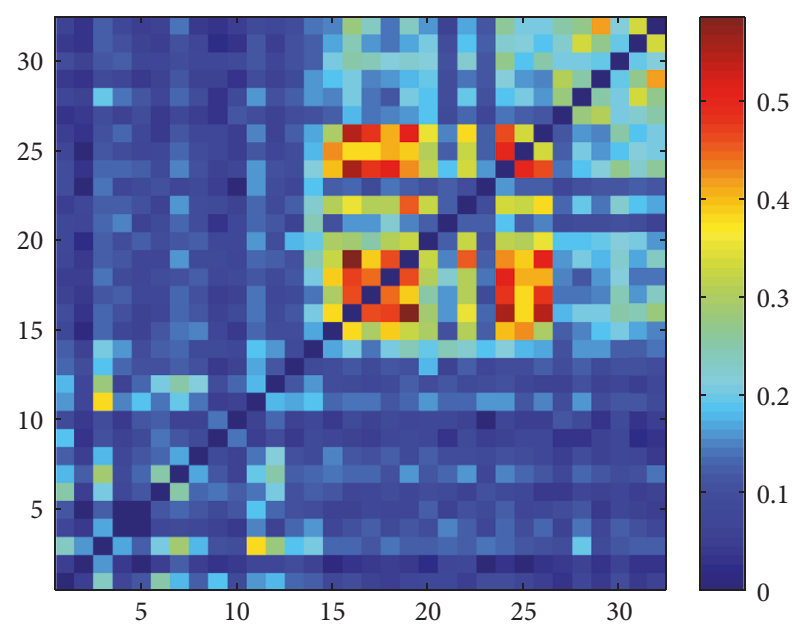

(c)

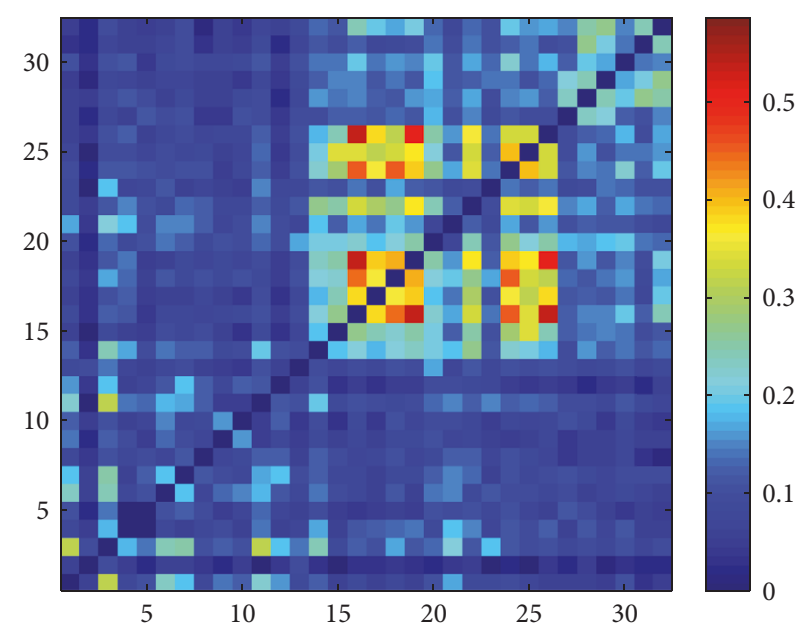

(b)

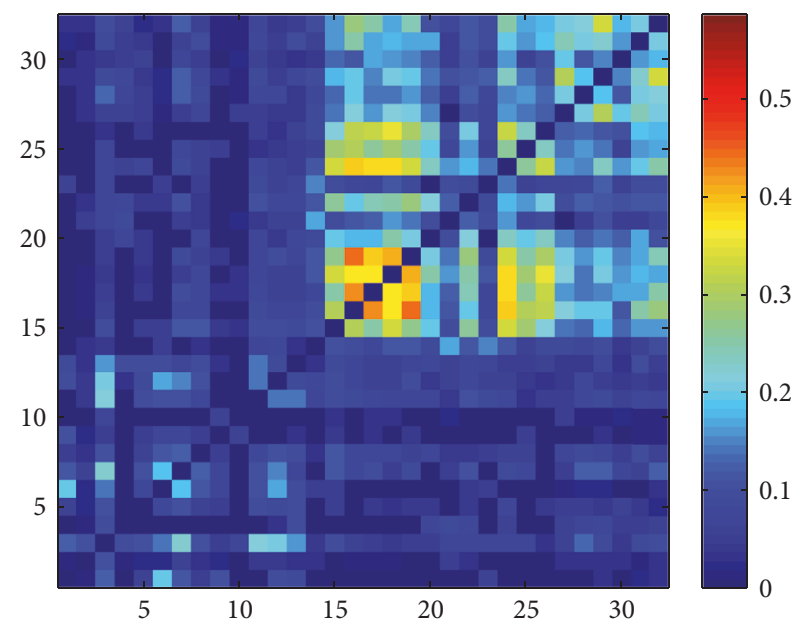

(d)

FIgure 6: The color maps of the contagion distribution in different windows. (a) The color map for the 5th window. (b) The color map for the 15th window. (c) The color map for the 25th window. (d) The color map for the 35th window.

on, becomes stronger in the middle stage, and weakens in the later stage. The European region experiences relatively strong contagion throughout.

We calculate the GACS and ACGCS values for the European, American, and Asian groups. In Figure 7, we can see that the values are low at first, followed by an uptrend. In the middle phase, we see a surge in values. There is a decline in the later stage. The mean GACS values for the European, American, and Asian groups are 3.9918, 3.2212, and 2.1805, respectively. Europe is the region which is worst impacted. The mean ACGCS values for Europe-America, America-Asia, and Asia-Europe are 0.1212, 0.0540, and 0.0593, respectively. The cross-contagion intensity between European and American regions is stronger than the intensity between these two regions and Asia.

Figure 8 presents the MaxSTs for the CMs of the 5th, 15th, 25 th, and 35th windows. The structures of these trees are different, but countries in one region still tend to connect with other countries from that region.
The JSC values of the MaxSTs in two consecutive windows are presented in Figure 9. The number on the row axis is the number of the sliding windows. We can see that the values fluctuate and the mean value of these windows is 0.7051 . Since each slide step covers two weeks, we can infer that, on average, the structures of the MaxSTs evolve steadily.

In order to examine the robustness of the results, we also apply $\alpha=0.01, \alpha=0.1$, and $\alpha=0.15$ in formula (6) to symbolize the returns and compute the results. Figure 10 shows the MaxSTs of the contagion distribution for the entire crisis period under these $\alpha$ values. Although the structures of these trees vary, countries still tend to cluster geographically.

Figure 11 shows the GACS and ACGCS values for $\alpha=$ $0.01, \alpha=0.1$, and $\alpha=0.15$. It can be observed that when $\alpha=0.1$ or $\alpha=0.15$, the curves are similar to the ones in Figure 7. However, the curves have flatter middle parts when $\alpha=0.01$. From Figures 11(a), 11(b), and 11(c), we find that European markets still experience the strongest contagion, whereas Asian markets show the weakest contagion. From 


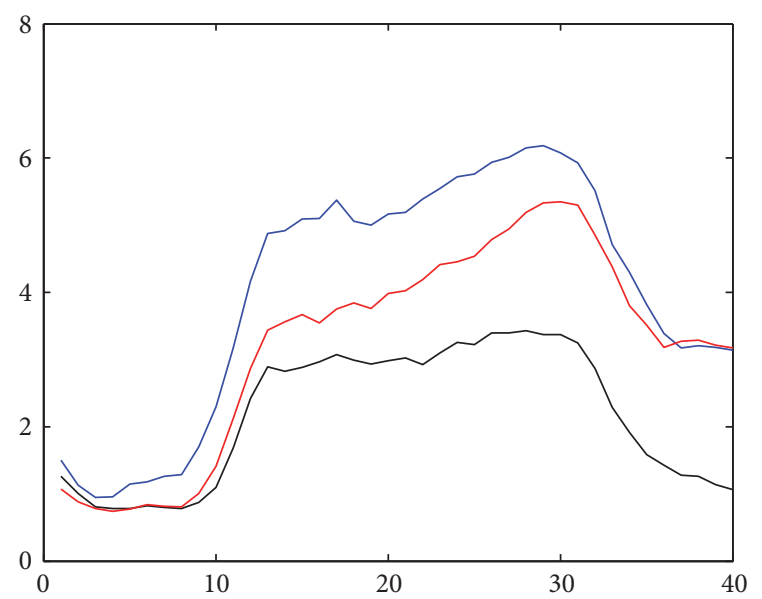

(a)

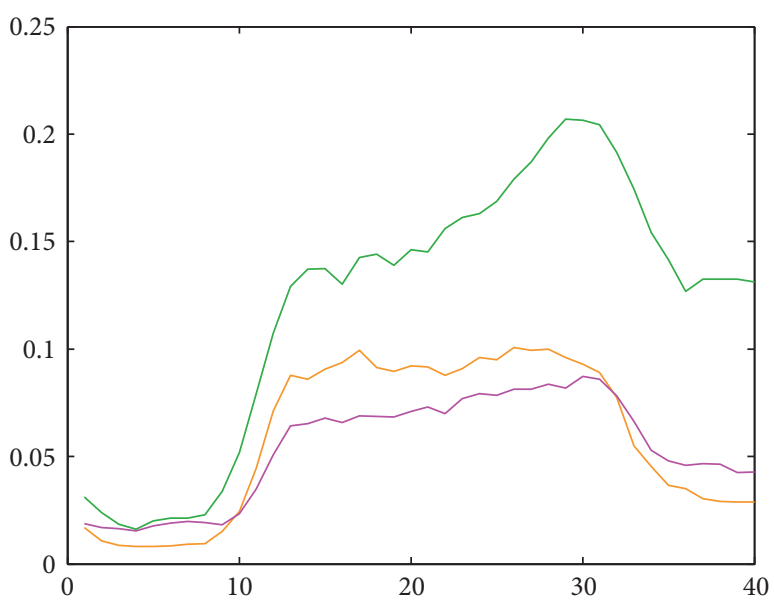

(b)

Figure 7: (a) The GACS values for European (blue line), Asian (black line), and American (red line) groups. (b) ACGCS values for the three groups: Europe-America group (green line), Asia-Europe group (yellow line), and America-Asia group (magenta line).

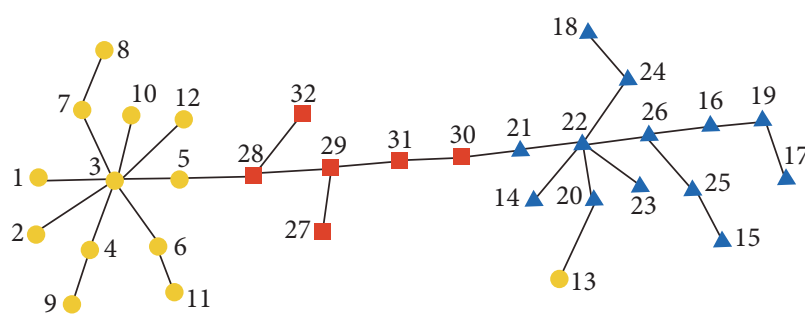

(a)

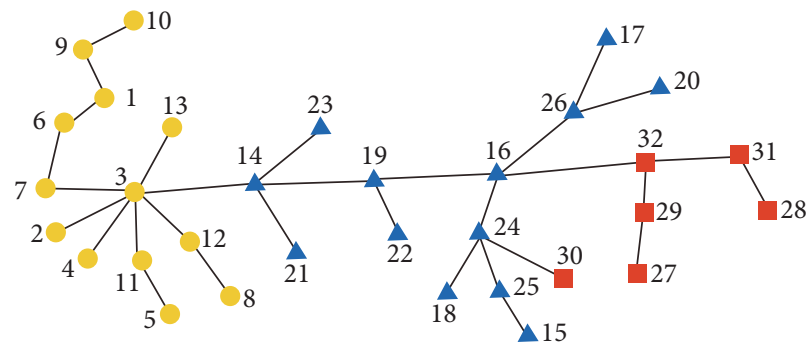

(c)

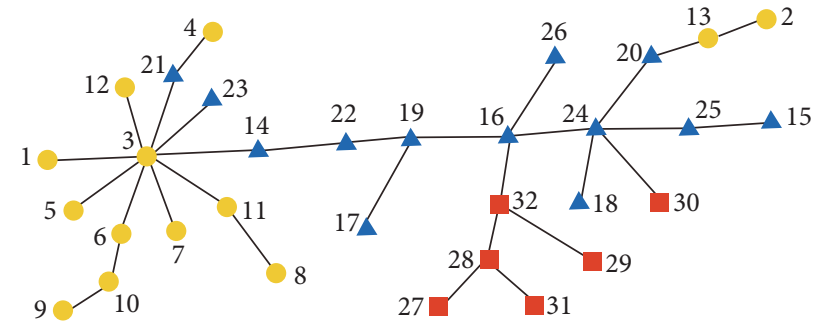

(b)

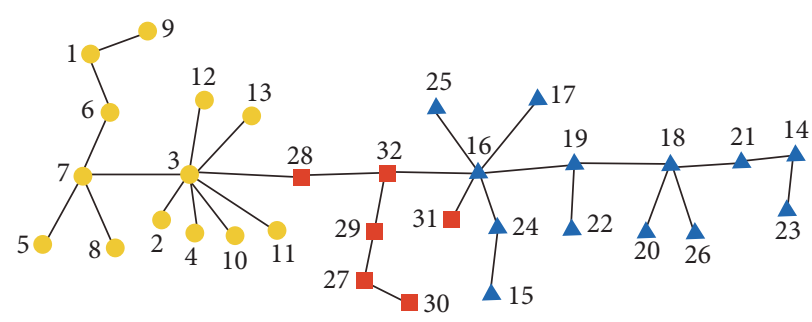

(d)

FIgURE 8: The MaxSTs for the contagion distribution in different windows. (a) The MaxST for the 5th window. (b) The MaxST for the 15th window. (c) The MaxST for the 25th window. (d) The MaxST for the 35th window. Asian and Oceanian markets are shown as yellow circles. European markets are shown as blue triangles. American markets are shown as red squares.

Figures 11(d), 11(e), and 11(f), it also can be observed that the cross-regional contagion strength with respect to Europe and America is stronger than that between Europe and Asia, as well as that between Asia and America.

\section{Conclusions}

Using the data from 32 stock markets, we utilized MI to research the distribution of the financial contagion in this paper. We symbolized the stock returns based on their quantiles and calculated the MI values for the stock markets.
Following the definition, we then applied the block bootstrap algorithm to test the financial contagion by examining whether there is a significant $\mathrm{MI}$ increase during the crisis period. We researched not only the contagion distribution for the entire crisis period, but also the evolution of the distribution by using sliding windows. Besides these, the robustness of the results was also analyzed.

The empirical results show that financial contagion is widespread in the stock markets and the countries that suffer contagion tend to cluster geographically. With the deepening of financial globalization, the interconnections 


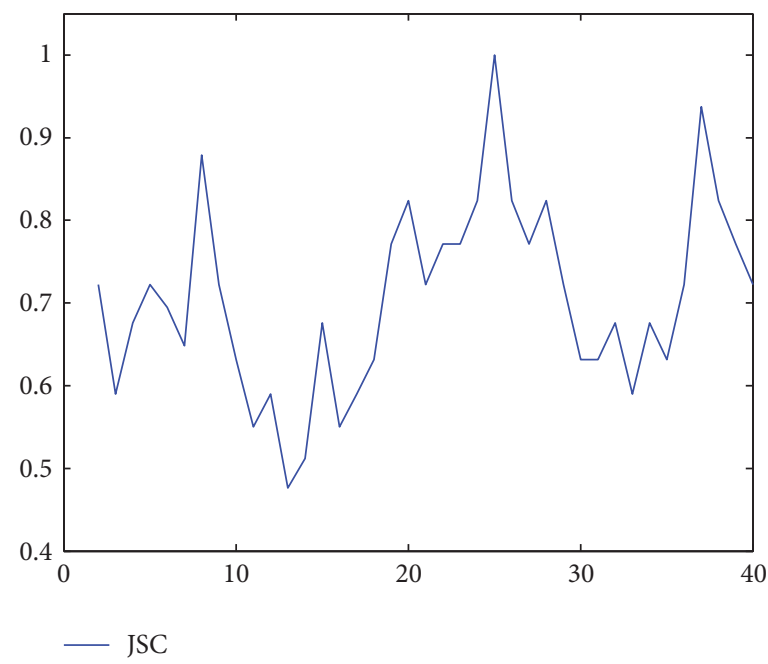

FIGURE 9: JSC values for the MaxSTs in sliding windows.

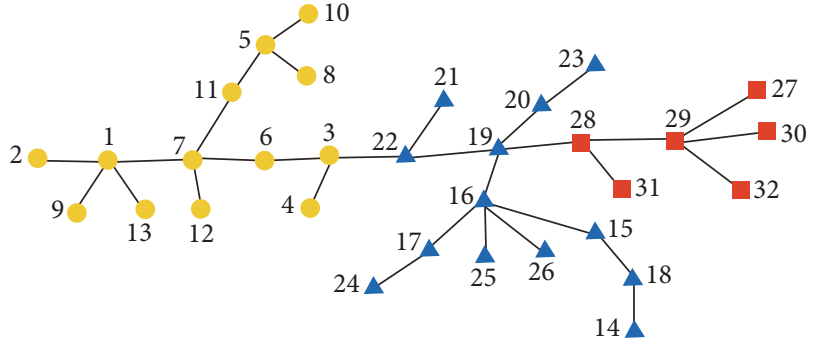

(a)

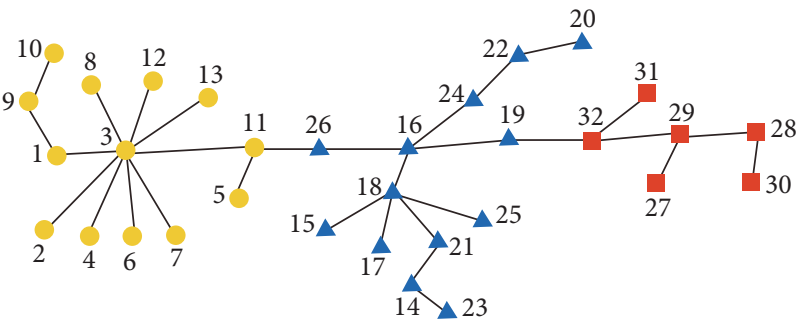

(b)

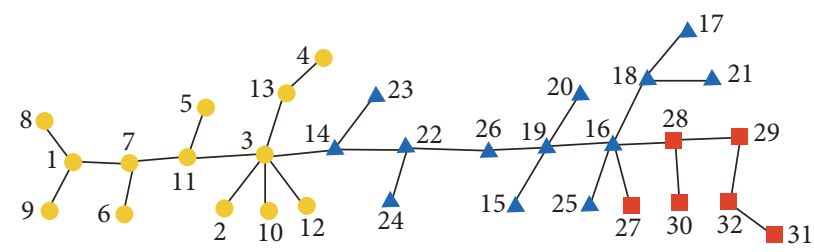

(c)

FIGURE 10: The MaxSTs of the contagion distribution for the entire crisis period using different $\alpha$ values in formula (6). (a) MaxST for $\alpha=0.01$. (b) MaxST for $\alpha=0.1$. (c) MaxST for $\alpha=0.15$. Asian and Oceanian markets are shown as yellow circles. European markets are shown as blue triangles. American markets are shown as red squares.

among different countries have increased greatly. This provides convenience for the transmission of financial distress [69]. Meanwhile, regional economic integration contributes to the sharing of contagion with neighboring markets. The distribution of contagion strength is found to be right skewed and leptokurtic, which suggests the heterogeneity of the contagion. The results indicate that Europe experienced strong contagion throughout the crisis period. Asia was the least affected region. Europe and America had a relatively higher level of cross-regional contagion. Since European economies are highly integrated, one country's financial turmoil easily propagates to other countries in the region. On the other hand, the interdependence of Asian stock markets is weaker than of America and Europe [70]. This not only abates the transmission of the contagion but also makes the Asian region a possible area for portfolios diversification. We also find that the contagion grows from weak to strong and then weakens again towards the end of the crisis. The mean JCS value is found to be high, indicating that, on average, most of the links of the MaxSTs in two consecutive windows remain intact. This implies that the spread of contagion between stock markets is not instantaneous. It tends to persist and evolve steadily.

This research suggests that it would be useful for policymakers to consider the impact of contagion from other markets, especially neighboring ones, when framing policies to deal with a financial crisis. Further, international cooperation and communication could help in halting the transmission of the financial turmoil. Our research also supplies reference for assets managers who diversify portfolios internationally. 


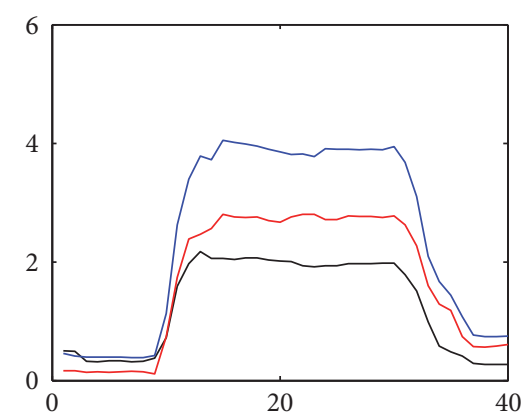

(a)

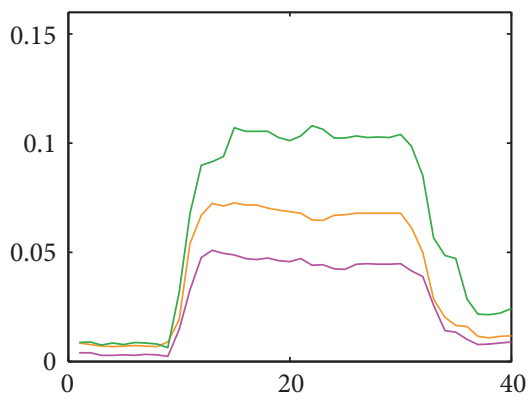

(d)

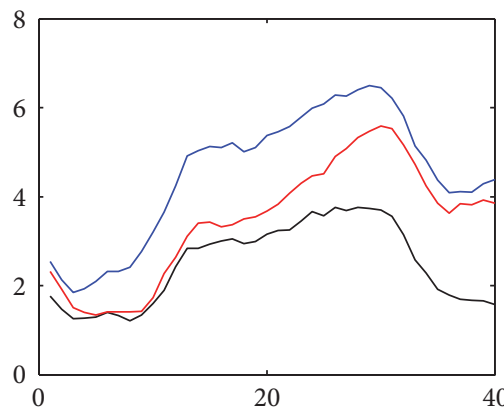

(b)

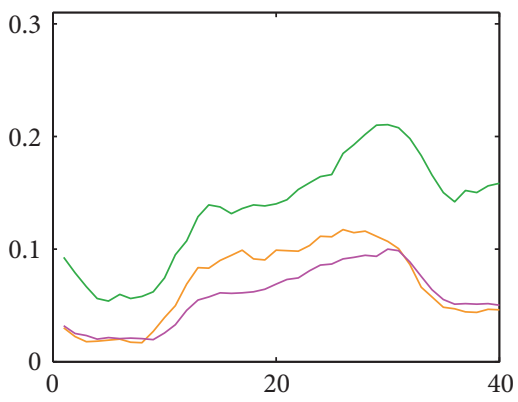

(e)

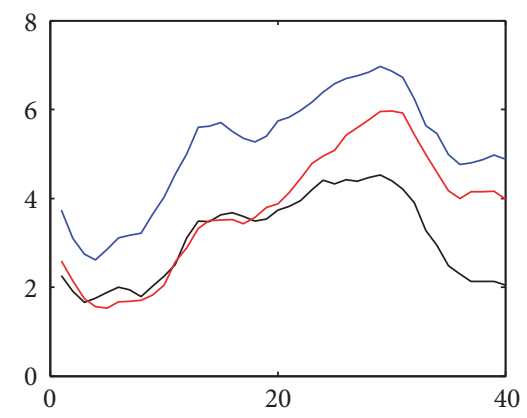

(c)

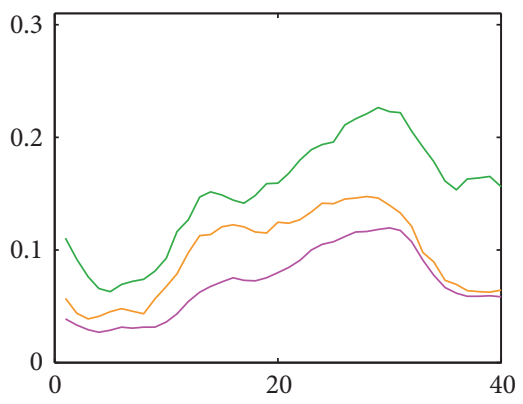

(f)

FIGURE 11: The GACS and ACGCS values using different $\alpha$ values in formula (6). (a) GACS values using $\alpha=0.01$. (b) GACS values using $\alpha=0.1$. (c) GACS values using $\alpha=0.15$. Europe (blue line), Asia (black line), and America (red line). (d) ACGCS values using $\alpha=0.01$. (e) ACGCS values using $\alpha=0.1$. (f) ACGCS values using $\alpha=0.15$. Europe-America group (green line), Asia-Europe group (yellow line), and America-Asia group (magenta line).

Investing in the markets which are less affected by financial contagion could be a possible way for avoiding losses. Furthermore, this study provides literature for understanding the mechanism of financial contagion.

\section{Conflicts of Interest}

The authors declare no conflicts of interest.

\section{Acknowledgments}

This work is supported by the National Natural Science Foundation of China (Grants nos. 71532004 and 71173060).

\section{References}

[1] G. S. Atsalakis, E. E. Protopapadakis, and K. P. Valavanis, "Stock trend forecasting in turbulent market periods using neurofuzzy systems," Operational Research, vol. 16, no. 2, pp. 245-269, 2016.

[2] H. Bickes, T. Otten, and L. C. Weymann, "The financial crisis in the German and English press: Metaphorical structures in the media coverage on Greece, Spain and Italy," Discourse \& Society, vol. 25, no. 4, pp. 424-445, 2014.

[3] M. Gallegati, "A wavelet-based approach to test for financial market contagion," Computational Statistics \& Data Analysis, vol. 56, no. 11, pp. 3491-3497, 2012.

[4] S. Celik, "The more contagion effect on emerging markets: The evidence of DCC-GARCH model," Economic Modelling, vol. 29, no. 5, pp. 1946-1959, 2012.
[5] K.-I. Choe, P. Choi, K. Nam, and F. Vahid, "Testing financial contagion on heteroskedastic asset returns in time-varying conditional correlation," Pacific-Basin Finance Journal, vol. 20, no. 2, pp. 271-291, 2012.

[6] K. J. Forbes and R. Rigobon, "No contagion, only interdependence: Measuring stock market comovements," Journal of Finance, vol. 57, no. 5, pp. 2223-2261, 2002.

[7] S. Mollah, A. M. M. S. Quoreshi, and G. Zafirov, "Equity market contagion during global financial and Eurozone crises: Evidence from a dynamic correlation analysis," Journal of International Financial Markets, Institutions \& Money, vol. 41, pp. 151-167, 2016.

[8] F. Durante, E. Foscolo, P. Jaworski, and H. Wang, "A spatial contagion measure for financial time series," Expert Systems with Applications, vol. 41, no. 8, pp. 4023-4034, 2014.

[9] B. M. Tabak, R. de Castro Miranda, and M. da Silva Medeiros, "Contagion in CDS, banking and equity markets," Economic Systems, vol. 40, no. 1, pp. 120-134, 2016.

[10] G. M. Caporale, A. Cipollini, and N. Spagnolo, "Testing for contagion: A conditional correlation analysis," Journal of Empirical Finance, vol. 12, no. 3, pp. 476-489, 2005.

[11] P. Arestis, G. M. Caporale, A. Cipollini, and N. Spagnolo, "Testing for financial contagion between developed and emerging markets during the 1997 East Asian crisis," International Journal of Finance \& Economics, vol. 10, no. 4, pp. 359-367, 2005.

[12] N. Van Horen, H. Jager, and F. Klaassen, "Foreign exchange market contagion in the Asian crisis: A regression-based approach," Review of World Economics, vol. 142, no. 2, pp. 374-401, 2006.

[13] W. Chen, Y. Wei, Q. Lang, Y. Lin, and M. Liu, "Financial market volatility and contagion effect: a copula-multifractal volatility 
approach," Physica A: Statistical Mechanics and Its Applications, vol. 398, pp. 289-300, 2014.

[14] M. Dungey and D. Gajurel, "Equity market contagion during the global financial crisis: Evidence from the world's eight largest economies," Economic Systems, vol. 38, no. 2, pp. 161-177, 2014.

[15] B. Støve, D. Tjøstheim, and K. O. Hufthammer, "Using local Gaussian correlation in a nonlinear re-examination of financial contagion," Journal of Empirical Finance, vol. 25, pp. 62-82, 2014.

[16] W. Ye, X. Liu, and B. Miao, "Measuring the subprime crisis contagion: evidence of change point analysis of copula functions," European Journal of Operational Research, vol. 222, no. 1, pp. 96103, 2012.

[17] X. Wen, Y. Wei, and D. Huang, "Measuring contagion between energy market and stock market during financial crisis: A copula approach," Energy Economics, vol. 34, no. 5, pp. 14351446, 2012.

[18] F. Guo, C. R. Chen, and Y. S. Huang, "Markets contagion during financial crisis: A regime-switching approach," International Review of Economics \& Finance, vol. 20, no. 1, pp. 95-109, 2011.

[19] S. Suh, "Measuring sovereign risk contagion in the Eurozone," International Review of Economics \& Finance, vol. 35, pp. 45-65, 2015.

[20] W. Ahmad, S. Sehgal, and N. R. Bhanumurthy, "Eurozone crisis and BRIICKS stock markets: Contagion or market interdependence?" Economic Modelling, vol. 33, pp. 209-225, 2013.

[21] G. Dewandaru, R. Masih, and A. M. M. Masih, "What can wavelets unveil about the vulnerabilities of monetary integration? A tale of Eurozone stock markets," Economic Modelling, vol. 52, pp. 981-996, 2016.

[22] P.-L. Shen, W. Li, X.-T. Wang, and C.-W. Su, "Contagion effect of the European financial crisis on China's stock markets: Interdependence and pure contagion," Economic Modelling, vol. 50, pp. 193-199, 2015.

[23] F. Li and H. Zhu, "Testing for financial contagion based on a nonparametric measure of the cross-market correlation," Review of Financial Economics, vol. 23, no. 3, pp. 141-147, 2014.

[24] S. M. Bartram and Y. Wang, "Another look at the relationship between cross-market correlation and volatility," Finance Research Letters, vol. 2, no. 2, pp. 75-88, 2005.

[25] S. Jayech, "The contagion channels of July-August-2011 stock market crash: a DAG-copula based approach," European Journal of Operational Research, vol. 249, no. 2, pp. 631-646, 2016.

[26] L. Maccone, D. Bruß, and C. Macchiavello, "Complementarity and correlations," Physical Review Letters, vol. 114, no. 13, Article ID 130401, 2015.

[27] P. Anagnostidis and C. J. Emmanouilides, "Nonlinearity in high-frequency stock returns: Evidence from the Athens Stock Exchange," Physica A: Statistical Mechanics and its Applications, vol. 421, pp. 473-487, 2015.

[28] I. Kojadinovic, "Agglomerative hierarchical clustering of continuous variables based on mutual information," Computational Statistics \& Data Analysis, vol. 46, no. 2, pp. 269-294, 2004.

[29] R.-B. Chen, M. Guo, W. K. Härdle, and S.-F. Huang, "COPICA-independent component analysis via copula techniques," Statistics and Computing, vol. 25, no. 2, pp. 273-288, 2015.

[30] A. Dionisio, R. Menezes, and D. A. Mendes, "Mutual information: a measure of dependency for nonlinear time series," Physica A: Statistical Mechanics and its Applications, vol. 344, no. 1-2, pp. 326-329, 2004.
[31] J. B. Kinney and G. S. Atwal, "Equitability, mutual information, and the maximal information coefficient," Proceedings of the National Acadamy of Sciences of the United States of America, vol. 111, no. 9, pp. 3354-3359, 2014.

[32] C. S. Hong and B. J. Kim, "Mutual information and redundancy for categorical data," Statistical Papers, vol. 52, no. 1, pp. 17-31, 2011.

[33] G. D. Tourassi, E. D. Frederick, M. K. Markey, and C. E. Floyd Jr., "Application of the mutual information criterion for feature selection in computer-aided diagnosis," Medical Physics, vol. 28, no. 12, pp. 2394-2402, 2001.

[34] N. Dowson and R. Bowden, "Mutual Information for LucasKanade Tracking (MILK): An inverse compositional formulation," IEEE Transactions on Pattern Analysis and Machine Intelligence, vol. 30, no. 1, pp. 180-185, 2008.

[35] P. Dames, D. Thakur, M. Schwager, and V. Kumar, "Playing fetch with your Robot: The ability of Robots to locate and interact with objects," IEEE Robotics and Automation Magazine, vol. 21, no. 2, pp. 46-52, 2014.

[36] S. D. S. Santos, D. Y. Takahashi, A. Nakata, and A. Fujita, "A comparative study of statistical methods used to identify dependencies between gene expression signals," Briefings in Bioinformatics, vol. 15, no. 6, pp. 906-918, 2013.

[37] K. R. Wollenberg and W. R. Atchley, "Separation of phylogenetic and functional associations in biological sequences by using the parametric bootstrap," Proceedings of the National Acadamy of Sciences of the United States of America, vol. 97, no. 7, pp. 32883291, 2000.

[38] J. Lee and D.-W. Kim, "Mutual Information-based multi-label feature selection using interaction information," Expert Systems with Applications, vol. 42, no. 4, pp. 2013-2025, 2015.

[39] J. Wang, B. Chen, Y. Wang et al., "Reconstructing regulatory networks from the dynamic plasticity of gene expression by mutual information," Nucleic Acids Research, vol. 41, no. 8, article e97, 2013.

[40] D. Aguilar, B. Oliva, and C. Marino Buslje, "Mapping the mutual information network of enzymatic families in the protein structure to unveil functional features," PLOS ONE, vol. 7, no. 7, Article ID e41430, 2012.

[41] P. Fiedor, "Mutual information rate-based networks in financial markets," Physical Review E: Statistical, Nonlinear, and Soft Matter Physics, vol. 89, no. 5, 2014.

[42] C. Yang, Y. Chen, W. Hao, Y. Shen, M. Tang, and L. Niu, "Effects of financial crisis on the industry sector of Chinese stock market-from a perspective of complex network," Modern Physics Letters, vol. 28, no. 13, Article ID 1450102, 13 pages, 2014.

[43] A. Kharrazi and B. D. Fath, "Measuring global oil trade dependencies: An application of the point-wise mutual information method," Energy Policy, vol. 88, pp. 271-277, 2016.

[44] P. Horta, S. Lagoa, and L. Martins, "The impact of the 2008 and 2010 financial crises on the Hurst exponents of international stock markets: Implications for efficiency and contagion," International Review of Financial Analysis, vol. 35, pp. 140-153, 2014.

[45] X. Jin, "The impact of 2008 financial crisis on the efficiency and contagion of Asian stock markets: A Hurst exponent approach," Finance Research Letters, vol. 17, pp. 167-175, 2016.

[46] T. C. Chiang, B. N. Jeon, and H. Li, "Dynamic correlation analysis of financial contagion: Evidence from Asian markets," Journal of International Money and Finance, vol. 26, no. 7, pp. 1206-1228, 2007. 
[47] S. Voronkova, "Equity market integration in Central European emerging markets: A cointegration analysis with shifting regimes," International Review of Financial Analysis, vol. 13, no. 5, pp. 633-647, 2004.

[48] M. Balcilar, R. Demirer, and S. Hammoudeh, "What drives herding in oil-rich, developing stock markets? Relative roles of own volatility and global factors," The North American Journal of Economics and Finance, vol. 29, pp. 418-440, 2014.

[49] L. Sandoval Jr., "To lag or not to lag? How to compare indices of stock markets that operate on different times," Physica A: Statistical Mechanics and its Applications, vol. 403, pp. 227-243, 2014.

[50] G.-J. Wang, C. Xie, and H. E. Stanley, "Correlation Structure and Evolution of World Stock Markets: Evidence from Pearson and Partial Correlation-Based Networks," Computational Economics, pp. 1-29, 2016.

[51] C. Nguyen, M. Ishaq Bhatti, and D. Henry, "Are Vietnam and Chinese stock markets out of the US contagion effect in extreme events?" Physica A: Statistical Mechanics and its Applications, vol. 480, pp. 10-21, 2017.

[52] A. F. Villaverde, J. Ross, F. Morán, and J. R. Banga, "MIDER: network inference with mutual information distance and entropy reduction," PLoS ONE, vol. 9, no. 5, Article ID e96732, 2014.

[53] R. Steuer, J. Kurths, C. O. Daub, J. Weise, and J. Selbig, “The mutual information: detecting and evaluating dependencies between variables," Bioinformatics, vol. 18, supplement 2, pp. S231-S240, 2002.

[54] T. Dimpfl and F. J. Peter, "The impact of the financial crisis on transatlantic information flows: An intraday analysis," Journal of International Financial Markets, Institutions \& Money, vol. 31, no. 1, pp. 1-13, 2014.

[55] A. Sensoy, C. Sobaci, S. Sensoy, and F. Alali, "Effective transfer entropy approach to information flow between exchange rates and stock markets," Chaos, Solitons \& Fractals, vol. 68, pp. 180$185,2014$.

[56] K.-H. Bae, G. A. Karolyi, and R. M. Stulz, "A new approach to measuring financial contagion," Review of Financial Studies, vol. 16, no. 3, pp. 717-763, 2003.

[57] S. M. Barbosa, "Trends in extreme mean sea level quantiles from satellite altimetry," Marine Geodesy, vol. 39, no. 2, pp. 165-177, 2016.

[58] F. Durante and E. Foscolo, "An analysis of the dependence among financial markets by spatial contagion," International Journal of Intelligent Systems, vol. 28, no. 4, pp. 319-331, 2013.

[59] M. F. Da Silva, É. J. De Area Leão Pereira, A. M. Da Silva Filho, A. P. N. De Castro, J. G. V. Miranda, and G. F. Zebende, "Quantifying the contagion effect of the 2008 financial crisis between the G7 countries (by GDP nominal)," Physica A: Statistical Mechanics and its Applications, vol. 453, pp. 1-8, 2016.

[60] J.-P. Kreiss and E. Paparoditis, "Bootstrap methods for dependent data: a review," Journal of the Korean Statistical Society, vol. 40, no. 4, pp. 357-378, 2011.

[61] H. Cheng, M. J. Small, and N. J. Pekney, "Application of nonparametric regression and statistical testing to identify the impact of oil and natural gas development on local air quality," Atmospheric Environment, vol. 119, pp. 381-392, 2015.

[62] C. Diks and J. DeGoede, "A general nonparametric bootstrap test for Granger causality," in In Global Analysis of Dynamical Systems, H. Broer, B. Krauskopf, and G. Vegter, Eds., pp. 391403, IoP Publishing, London, UK, 2001.
[63] J. A. Mills and S. Zandvakili, "Statistical inference via bootstrapping for measures of inequality," Journal of Applied Econometrics, vol. 12, no. 2, pp. 133-150, 1997.

[64] P. E. Shrout and N. Bolger, "Mediation in experimental and nonexperimental studies: new procedures and recommendations," Psychological Methods, vol. 7, no. 4, pp. 422-445, 2002.

[65] C. Yang, X. Zhu, Q. Li, Y. Chen, and Q. Deng, "Research on the evolution of stock correlation based on maximal spanning trees," Physica A: Statistical Mechanics and its Applications, vol. 415, pp. 1-18, 2014.

[66] G. Cao, Q. Zhang, and Q. Li, "Causal relationship between the global foreign exchange market based on complex networks and entropy theory," Chaos, Solitons \& Fractals, vol. 99, pp. 36-44, 2017.

[67] D. Sarkar, A. De, C. K. Chanda, and S. Goswami, "Kruskal's Maximal Spanning Tree Algorithm for Optimizing Distribution Network Topology to Improve Voltage Stability," Electric Power Components and Systems, vol. 43, no. 17, pp. 1921-1930, 2015.

[68] K. Berlin, S. Koren, C.-S. Chin, J. P. Drake, J. M. Landolin, and A. M. Phillippy, "Assembling large genomes with singlemolecule sequencing and locality-sensitive hashing," Nature Biotechnology, vol. 33, no. 6, pp. 623-630, 2015.

[69] P. Glasserman and H. P. Young, "How likely is contagion in financial networks?" Journal of Banking \& Finance, vol. 50, pp. 383-399, 2015.

[70] L. Junior, A. Mullokandov, and D. Kenett, "Dependency Relations among International Stock Market Indices," Journal of Risk and Financial Management, vol. 8, no. 2, pp. 227-265, 2015. 


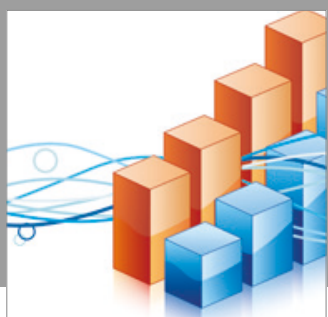

Advances in

Operations Research

vatersals

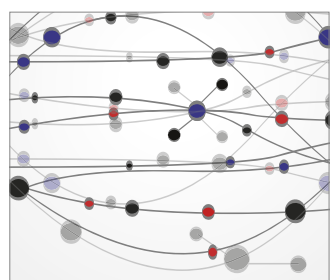

\section{The Scientific} World Journal
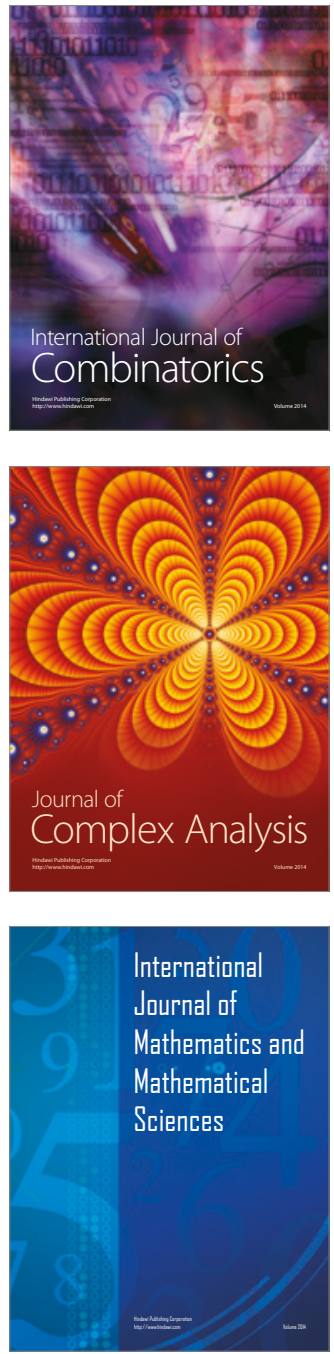
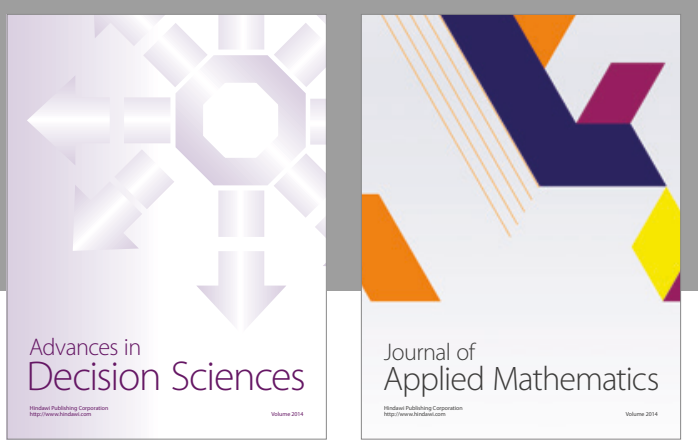

Algebra

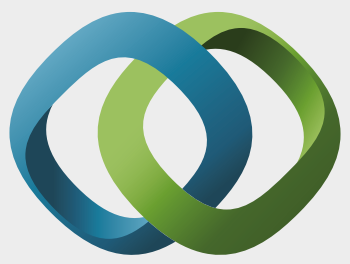

\section{Hindawi}

Submit your manuscripts at

https://www.hindawi.com
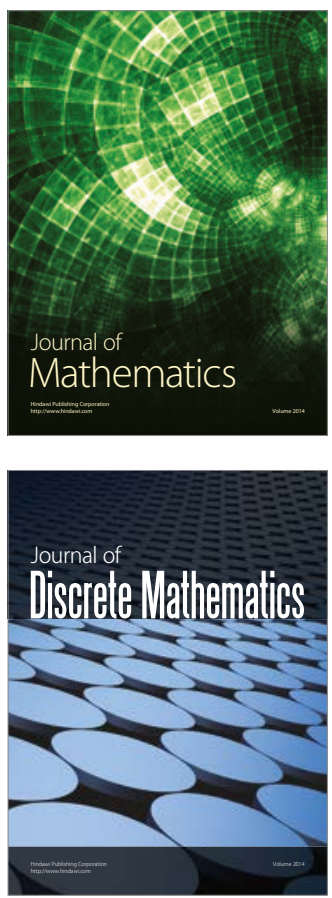

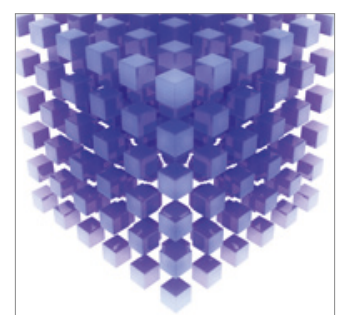

Mathematical Problems in Engineering
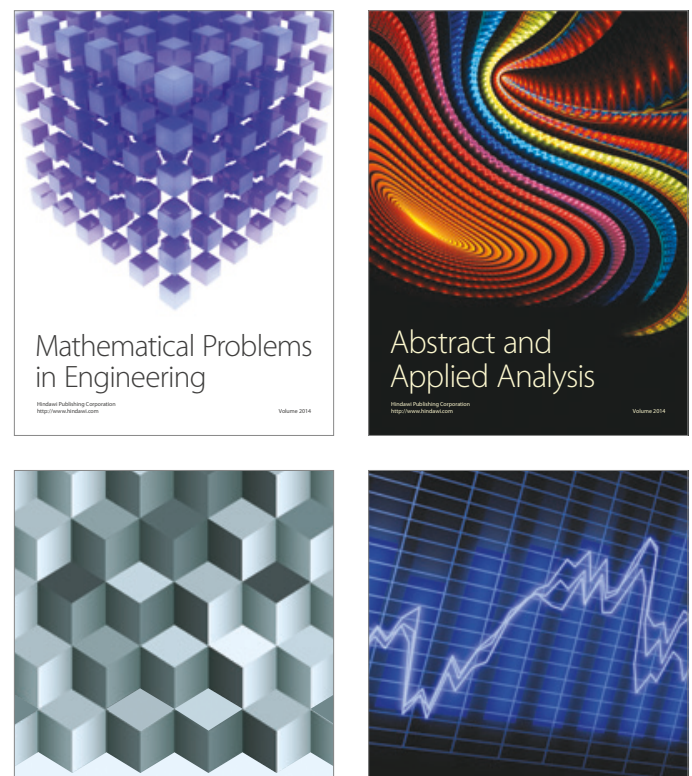

Journal of

Function Spaces

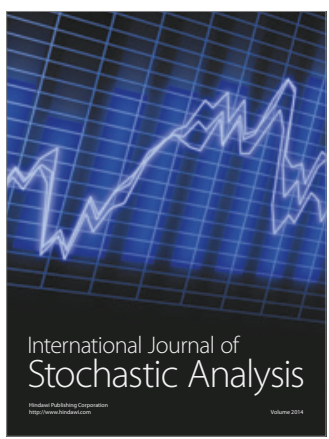

Probability and Statistics
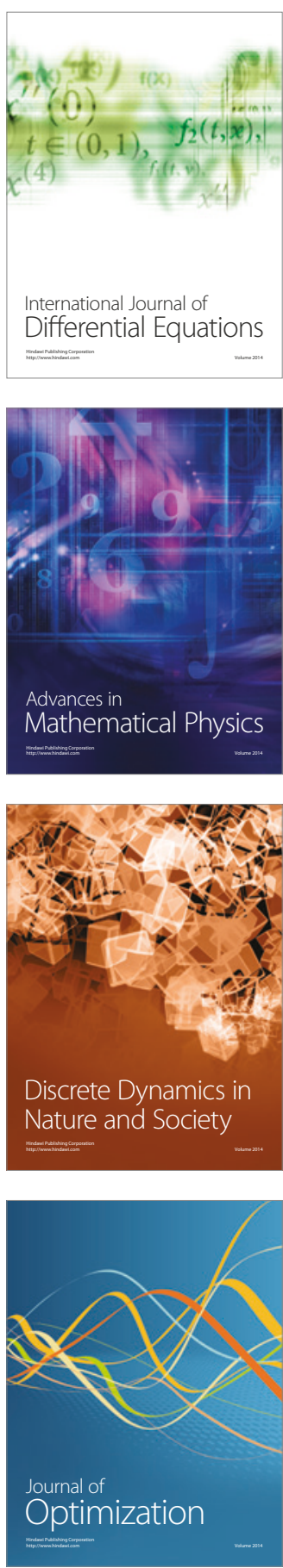